\title{
INFLUÊNCIA DO CALÇADO DE SALTO ALTO SOBRE A POSTURA ESTÁTICA E DURANTE A MARCHA HUMANA: REVISÃO DE LITERATURA
}

Adirléia Machado ALVES 1

Adriely Aline Lopes CORRÊA ${ }^{2}$

Luís Henrique Sales OLIVEIRA ${ }^{3}$

\begin{abstract}
1Pós Graduada em Fisioterapia Traumato- Ortopédica e Esportiva pelo Centro Universitário de Itajubá - FEPI, a_malves@yahoo.com.br

${ }^{2}$ Pós Graduada em Fisioterapia Traumato - Ortopédica e Esportiva pelo Centro Universitário de Itajubá - FEPI, adrielyalinel@yahoo.com.br

${ }^{3}$ Doutorado em Cirurgia Plástica pela Universidade Federal de São Paulo - UNIFESP, lhfisio@ hotmail.com
\end{abstract}

Recebido em: 30/10/2013 - Aprovado em: 22/12/2013 - Disponibilizado em: 15/01/2014

\begin{abstract}
Resumo: Este trabalho propôs-se a realizar uma revisão da literatura sobre alterações posturais estáticas e o comportamento biomecânico da marcha humana durante a utilização de calçados de salto alto. Materiais e Métodos: Este estudo é do tipo longitudinal e retrospectivo. Para isso, realizou-se um levantamento bibliográfico, de julho de 2012 a abril de 2013, através dos sistemas nacionais (BIREME e Lilacs) e internacionais (PubMed) que se referem às publicações dos últimos 8 anos. Neste estudo, encontramos 39 artigos, dos quais utilizamos 23 artigos que trataram de forma clara o assunto. Resultados: de um modo geral, mudanças significativas são observadas na biomecânica da marcha durante a utilização de calçados de salto alto submetendo o corpo à condições não fisiológicas que necessitam de constantes adaptações e acomodações nos componentes musculares e articulares da coluna vertebral e nos membros inferiores durante o seu uso. Conclusão: A presente revisão de literatura trouxe informações importantes a respeito das alterações músculo esqueléticas de coluna lombar, dos membros inferiores e das alterações de equilíbrio corporal advindas do uso de salto alto. Dessa forma, o uso do salto alto pode predispor a população feminina à lesões, artralgias e alterações posturais. No entanto, sugerimos estudos futuros para maior compreensão da marcha humana para aperfeiçoamento técnico do movimento corporal nas diversas áreas da saúde.
\end{abstract}

Palavras-chave: Marcha. Postura. Coluna Vertebral. Sapatos. Salto Alto.

\begin{abstract}
This work aimed to conduct a review of the literature on static postural and biomechanical behavior of the human gait during the use of high-heeled shoes. Materials and Methods: This study is a longitudinal and retrospective. For this, we performed a bibliographic surve, July 2012 to April 2013, through the national systems (BIREME and Lilacs) and international (PubMed) that refer to the publications of the last 8 years. In this study, we found 39 articles, 23 of which use articles that dealt with the subject clearly. Results: in general, significant changes are observed in the gait biomechanics during the use of high-heeled shoes subjecting the body to non-physiological conditions that require constant adaptation and accommodation components in muscles and joints of the spine and lower limbs during their use. Conclusion: This review of the literature provided important information about the changes musculoskeletal lumbar spine, lower limb and body balance changes arising from the use of high heels. Thus, the use of high heels may predispose the population fe $\neg$ minina the lesions, arthralgia, and postural changes . However, we suggest further studies for better understanding of human gait for technical improvement of body movement in different areas of health.
\end{abstract} Keys-word: March. Posture. Spine. Shoes. High Heels.

\section{I - INTRODUÇÃO}

A marcha é considerada uma tarefa funcional que exige interação e coordenação entre muitas das principais articulações do corpo humano (MORAES FILHO; REIS; KAWAMURA, 2010).

Ao observar a cinética da marcha, o pé constitui a base de apoio e propulsão, sendo considerado um amortecedor de impactos por apresentar arcos plantares que realizam transferências de cargas para 3 regiões: retropé, mediopé e antepé (LUNES et al., 2008) e (NAZARIO; SANTOS; ÁVILA, 2010).

Atualmente observa-se uma crescente redução da mobilidade fisiológica dos pés, causada possivelmente pelo uso de calçados e pelo sedentarismo. (VIANNA; GREVE, 2006).

Variações na forma, consistência e material usado na fabricação do calçado e a 
dureza do solo também influem nos sintomas de cansaço, dor lombar e plantar durante a utilização dos mesmos (TEDESCHI, FILHO et al., 2007).

A postura inadequada durante as atividades realizadas com salto alto pode levar a uma aceleração do processo de desgaste sofrido pelo aparelho locomotor. (FAVERA et al., 2010).

O salto alto, por apresentar valor estético entre as mulheres, tem sido muito utilizado, tornando-se uma opção diária no ambiente de trabalho (TEDESCHI, FILHO et al. 2007); (LUNES et al., 2008).

O tipo de calçado utilizado pode influenciar o sistema musculoesquelético podendo levar a alteração da angulação da coluna lombar, da inclinação da pelve, da articulação do joelho, na angulação tíbiotársica e na conformação do arco plantar. O uso do salto alto pode predispor a população feminina à lombalgia, às metatarsalgias, às calosidades, à dor plantar, ao hálux valgo e á entorse de tornozelo (LIMANA et al., 2012).

Vários estudos estão sendo desenvolvidos para uma melhor compreensão das características dos padrões da marcha. Algumas situações como a utilização de diferentes tipos de calçados, por fazerem parte da rotina da vida diária de muitas mulheres, podem alterar as características normais do padrão biomecânico da marcha e da postura estática (MANN; TEIXEIRA; MOTA, 2008).

\section{II - OBJETIVO}

Realizar uma revisão da literatura sobre alterações posturais estáticas e o comportamento biomecânico da marcha humana durante a utilização de calçados de salto alto.

\section{III - MATERIAIS E MÉTODOS}

Trata-se de uma pesquisa do tipo longitudinal e retrospectivo. Realizou-se um levantamento bibliográfico, de julho de 2012 a abril de 2013, através dos sistemas nacionais (BIREME e Lilacs) e internacionais (PubMed) que se referem às publicações dos últimos 11 anos que tratassem do tema de forma clara.

A seleção dos descritores utilizados, no processo de revisão foi efetuada mediante consulta ao DECs (descritores de assunto em ciências da saúde da BIREME). Nas buscas, os seguintes descritores, em língua portuguesa e inglesa foram considerados: "Marcha", "Postura" e "Sapatos".

Neste estudo, encontramos 39 artigos, dos quais utilizamos 28 artigos que trataram de forma clara o assunto. Os critérios de inclusão foram: artigos originais publicadas dentro dos últimos 11 anos que relatassem sobre os aspectos da marcha humana normal, bem como as alterações da marcha humana e da postura corporal estática durante o uso de calçados de salto alto. Os 11 artigos que não encaixassem nesses aspectos foram excluídos do estudo. 


\section{IV - RESULTADOS}

De um modo geral, mudanças significativas são observadas na biomecânica da marcha durante a utilização de calçados de salto alto submetendo o corpo à condições não fisiológicas que necessitam de constantes adaptações e acomodações nos componentes musculares e articulares da coluna vertebral e nos membros inferiores durante o seu uso.

Em nosso estudo, foram identificadas as principais alterações biomecânicas do uso de salto alto na cinemática da marcha.

No quadro Quadro I, listamos alguns estudos encontrados na nossa pesquisa, bem como seus respectivos resultados.

Quadro I - Resultado da Pesquisa

\begin{tabular}{|c|c|c|c|}
\hline $\begin{array}{l}\text { AUTOR E } \\
\text { REVISTA }\end{array}$ & OBJETIVO & MÉTODO & RESULTADO \\
\hline $\begin{array}{l}\text { BERTOCELLO, } \\
\text { D. et al. } \\
\text { Fisioterapia e } \\
\text { Pesquisa. } 2009 .\end{array}$ & $\begin{array}{l}\text { Verificar } \\
\text { alterações de } \\
\text { equilíbrio e } \\
\text { retração muscular } \\
\text { no uso de salto } \\
\text { alto diariamente. }\end{array}$ & $\begin{array}{l}\text { Flexibilidade: teste de Wells; } \\
\text { equilíbrio: teste de romberg e } \\
\text { tempo de uso de sapato de } \\
\text { salto alto de } 30 \text { voluntárias. }\end{array}$ & $\begin{array}{l}\text { Os resultados foram } \\
\text { correlacionados: Quanto } \\
\text { maior o tempo de uso do } \\
\text { calçado, menor o alcance } \\
\text { horizontal e menor o } \\
\text { tempo de equilíbrio em pé } \\
\text { e quanto maior o alcance } \\
\text { maior o tempo de } \\
\text { equilíbrio. }\end{array}$ \\
\hline $\begin{array}{l}\text { LUNES, D. H. } \\
\text { et al. Revista } \\
\text { Brasileira de } \\
\text { Fisioterapia. } \\
2008 .\end{array}$ & $\begin{array}{l}\text { Avaliar } \\
\text { influencia do uso } \\
\text { de salto alto nas } \\
\text { alterações } \\
\text { posturais por } \\
\text { meio da } \\
\text { fotogrametria } \\
\text { computadorizada. }\end{array}$ & $\begin{array}{l}\text { Grupo 1: } 20 \text { mulheres que } \\
\text { utilizam salto alto com } \\
\text { frequência; Grupo } 2: 20 \text { que } \\
\text { utilizam salto alto } \\
\text { esporadicamente. } 2 \text { grupos } \\
\text { fotografados a) descalço, b) } \\
\text { salto agulha e c) salto } \\
\text { plataforma. }\end{array}$ & $\begin{array}{l}\text { Posicionamento da cabeça } \\
(\mathrm{p}<0,01) \text { nos } 2 \text { grupos: } \\
\text { quanto menor sua medida, } \\
\text { mais a cabeça é anterio- } \\
\text { rizada. Diferença do } \\
\text { alinhamento de joelho } \\
\text { entre o sapato agulha e os } \\
\text { pés descalços no grupo } 1 \\
\text { ( }<<0,05) \text { posicionamento } \\
\text { do tornozelo: diferença } \\
\text { em todos os tipos de } \\
\text { calçado }(p<0,01) \text {. }\end{array}$ \\
\hline $\begin{array}{l}\text { JOÃO, S.M.A. } \\
\text { et al. } \\
\text { Fisioterapia e } \\
\text { Pesquisa. } 2012 .\end{array}$ & $\begin{array}{l}\text { Analisar a } \\
\text { influência do } \\
\text { calçado de salto } \\
\text { alto no arco } \\
\text { longitudinal } \\
\text { medial do pé. }\end{array}$ & $\begin{array}{l}\text { Grupo controle: } 54 \text { não } \\
\text { usuárias } \\
\text { experimental: } 28 \text { usuárias de } \\
\text { salto alto. Arco longitudinal } \\
\text { medial analisado pelo índice } \\
\text { de Chippaux-Smirak (ICS) e } \\
\text { pelo índice do arco de } \\
\text { Cavanagh \& Rodgers (ICR), } \\
\text { antes e depois do uso de salto } \\
\text { anabella por um período de } 30 \\
\text { minutos. }\end{array}$ & $\begin{array}{l}\text { Análise intragrupo, } \\
\text { comparando-se o pé } \\
\text { direito com o esquerdo, } \\
\text { foi encontrada diferença } \\
\text { significante apenas no } \\
\text { grupo controle na situação } \\
\text { antes do uso da sandália } \\
\text { de salto alto. Ao ser feita a } \\
\text { comparação entre as } \\
\text { situações antes e depois } \\
\text { do uso do salto houve } \\
\text { diferença significante no } \\
\text { pé esquerdo do Grupo } \\
\text { Controle. }\end{array}$ \\
\hline
\end{tabular}




\begin{tabular}{|c|c|c|c|}
\hline $\begin{array}{l}\text { CANDOTTI, } \\
\text { C.T. et al. } \\
\text { Revista } \\
\text { Brasileira de } \\
\text { Ciência e } \\
\text { esporte, } 2012 .\end{array}$ & $\begin{array}{l}\text { Verificar a } \\
\text { ativação e a co- } \\
\text { contração } \\
\text { muscular dos } \\
\text { músculos tibial } \\
\text { anterior e } \\
\text { gastrocnêmio } \\
\text { lateral durante a } \\
\text { marcha, } \\
\text { utilizando } \\
\text { diferentes } \\
\text { calçados. }\end{array}$ & $\begin{array}{l}9 \text { mulheres caminharam sobre } \\
\text { uma esteira ergométrica: sem } \\
\text { calçado, com salto baixo }(6 \\
\mathrm{cm}) \text { e com salto alto }(9 \mathrm{~cm}), \\
\text { sendo simultaneamente } \\
\text { registrados sinais } \\
\text { eletromiográficos do tibial } \\
\text { anterior e gastrocnêmio } \\
\text { lateral. }\end{array}$ & $\begin{array}{l}\text { Independente da altura do } \\
\text { salto houve maior } \\
\text { ativação do gastrocnêmio } \\
\text { lateral em comparação } \\
\text { com o tibial anterior; o } \\
\text { músculo gatrocnêmio } \\
\text { lateral apresentou maior } \\
\text { ativação com o calçado de } \\
\text { salto alto, em comparação } \\
\text { a situação com os pés } \\
\text { descalços. Portanto quanto } \\
\text { maior a altura do salto, } \\
\text { maiores percentuais de co- } \\
\text { contração. }\end{array}$ \\
\hline $\begin{array}{l}\text { MINOSSI, } \\
\text { C.E.S. et al. } \\
\text { Fisioterapia e } \\
\text { Pesquisa, } 2012 \text {. }\end{array}$ & $\begin{array}{l}\text { Identificar a pos- } \\
\text { tura das } \\
\text { curvaturas da } \\
\text { coluna torácica e } \\
\text { lombar de } \\
\text { estudantes e } \\
\text { comparar esta } \\
\text { postura nas situ- } \\
\text { ações com } \\
\text { calçado de salto } \\
\text { alto e com os pés } \\
\text { descalços. }\end{array}$ & $\begin{array}{l}\text { Avaliação postural de } \\
\text { estudantes utilizando } \\
\text { instrumento arcômetro, nas } \\
\text { situações com salto alto e com } \\
\text { pés descalçosna postura } \\
\text { estática em ortostatismo. }\end{array}$ & $\begin{array}{l}\text { O uso de salto alto não } \\
\text { modificou os ângulos das } \\
\text { curvaturas da coluna } \\
\text { vertebral. }\end{array}$ \\
\hline $\begin{array}{l}\text { LIMANA, M.D. } \\
\text { et al. } \\
\text { Fisioterapia e } \\
\text { Pesquisa, } 2012 \text {. }\end{array}$ & $\begin{array}{l}\text { Comparar a } \\
\text { cinemática do } \\
\text { tornozelo em } \\
\text { diferentes } \\
\text { calçados. }\end{array}$ & $\begin{array}{l}10 \text { universitárias, que } \\
\text { caminharam sobre uma esteira } \\
\text { utilizando um tênis e três } \\
\text { sandálias do tipo tamanco, } \\
\text { com saltos de } 3,7 \text { e } 10 \mathrm{~cm} \text { e } \\
\text { identificados picos de mo- } \\
\text { vimento do tornozelo } \\
\text { referentes à dorsiflexão e à } \\
\text { flexão plantar. }\end{array}$ & $\begin{array}{l}\text { Com o aumento da altura } \\
\text { do salto, há uma } \\
\text { acentuação do angulo do } \\
\text { tornozelo durante a flexão } \\
\text { plantar e uma flexão } \\
\text { plantar sustentada no } \\
\text { momento da primeira } \\
\text { dorsiflexão na marcha. }\end{array}$ \\
\hline $\begin{array}{l}\text { MORAES et al. } \\
\text { Fisioterapia e } \\
\text { movimento. } \\
2010 .\end{array}$ & $\begin{array}{l}\text { Verificar se } \\
\text { diferentes tipos } \\
\text { de calçados são } \\
\text { capazes de alterar } \\
\text { a biomecânica } \\
\text { estática a partir } \\
\text { da avaliação } \\
\text { postural. }\end{array}$ & $\begin{array}{l}15 \text { mulheres submetidas a } \\
\text { uma avaliação postural } \\
\text { estática a partir do programa } \\
\text { Software para Análise } \\
\text { Postural utilizando salto alto, } \\
\text { salto baixo, tênis, chinelo e } \\
\text { descalça. }\end{array}$ & $\begin{array}{l}\text { Os resultados mostraram } \\
\text { que não houve diferença } \\
\text { significativa na postura } \\
\text { estática com os tipos de } \\
\text { calçados e descalço. }\end{array}$ \\
\hline $\begin{array}{l}\text { PEZZAN, } \\
\text { P.A.O., } \\
\text { SACCO, I.C.N., } \\
\text { JOÃO, S.M.A. } \\
\text { Revista } \\
\text { Brasielrira de } \\
\text { Fisioterapia, } \\
\text { 2009. }\end{array}$ & $\begin{array}{l}\text { Correlacionar a } \\
\text { postura dos pés } \\
\text { com o arco } \\
\text { plantar de } \\
\text { adolescentes } \\
\text { usuárias e não } \\
\text { usuárias de } \\
\text { calçados de salto }\end{array}$ & $\begin{array}{l}36 \text { adolescentes, } 16 \text { no grupo } \\
\text { de não usuárias e } 20 \text { no grupo } \\
\text { de usuárias de salto alto tipo } \\
\text { anabella. A postura do pé foi } \\
\text { analisada por fotos em dois } \\
\text { momentos: descalça e calçada } \\
\text { com salto alto. }\end{array}$ & $\begin{array}{l}\text { O ângulo do retropé se } \\
\text { apresentou varo após a } \\
\text { colocação do salto alto em } \\
\text { ambos os grupos. O grupo } \\
\text { de usuárias apresenta um } \\
\text { ângulo de varo de retropé } \\
\text { maior que as não usuárias } \\
\text { em ambas as condições. }\end{array}$ \\
\hline
\end{tabular}




\begin{tabular}{|c|c|c|c|}
\hline & alto. & & $\begin{array}{l}\text { As usuárias possuem } \\
\text { arcos plantares mais } \\
\text { elevados. }\end{array}$ \\
\hline $\begin{array}{l}\text { PEGORETTI } \text { et } \\
\text { al. Revista de } \\
\text { Ciências } \\
\text { médicas. } 2005 .\end{array}$ & $\begin{array}{lr}\text { Verificar } & \text { as } \\
\text { adaptações } & \text { que } \\
\text { ocorrem } & \text { na } \\
\text { lordose } & \text { lombar } \\
\text { sob a influência } \\
\text { de } & \text { diferente } \\
\text { altura de } & \text { saltos } \\
\text { de } & \text { calçados } \\
\text { durante a marcha } \\
\text { na r esteira } \\
\text { ergométrica } \\
\end{array}$ & $\begin{array}{l}\text { Três candidatas caminharam } \\
\text { em uma esteira ergométrica } \\
\text { em } 6 \text { situações diferentes: } 1 \\
\text { descalça e } 5 \text { com calçados de } \\
\text { diferentes saltos. Filmadas } \\
\text { com câmera. }\end{array}$ & $\begin{array}{l}\text { O aumento da altura dos } \\
\text { saltos provocou nas } \\
\text { candidatas uma retificação } \\
\text { na lordose lombar durante } \\
\text { a marcha na esteira } \\
\text { ergométrica. }\end{array}$ \\
\hline $\begin{array}{l}\text { MORAES, } \\
\text { G.S.F. et al., } \\
2012 . \\
\text { Fisioterapia e } \\
\text { Movimento. }\end{array}$ & $\begin{array}{l}\text { O objetivo deste } \\
\text { estudo foi avaliar } \\
\text { a atividade } \\
\text { eletromiográfica } \\
\text { de } \\
\text { músculos da } \\
\text { perna e eretores } \\
\text { da espinha } \\
\text { associada a tipos } \\
\text { de calçados e ao } \\
\text { andar descalço, } \\
\text { nos diferentes } \\
\text { planos de } \\
\text { locomoção, nas } \\
\text { situaçóes pré e } \\
\text { pós-fadiga }\end{array}$ & $\begin{array}{l}\text { Estudo observacional com } 15 \\
\text { sedentárias, analisando os } \\
\text { músculos tibial anterior, } \\
\text { gastrocnêmio medial e lateral } \\
\text { e eretores da espinha. A } \\
\text { atividade muscular foi } \\
\text { avaliada durante a marcha em } \\
\text { superfície plana, subindo e } \\
\text { descendo escada e rampa. Os } \\
\text { calçados utilizados foram } \\
\text { salto alto, salto baixo, tênis, } \\
\text { chinelo e descalço. }\end{array}$ & $\begin{array}{l}\text { Músculos da perna } \\
\text { apresentaram maior } \\
\text { atividade eletromiográfica } \\
\text { na situação de pré-fadiga } \\
\text { dos MMII, e os eretores } \\
\text { da espinha, na situação } \\
\text { pós-fadiga dos MMII, } \\
\text { na maioria das condições } \\
\text { e situações. }\end{array}$ \\
\hline $\begin{array}{l}\text { Edwards L. et } \\
\text { al. Journal of } \\
\text { Orthopaedic } \\
\text { Surgery and } \\
\text { Research, } 2008 .\end{array}$ & $\begin{array}{l}\text { Investigar o } \\
\text { efeito do calçado } \\
\text { de salto de } \\
\text { diferentes alturas } \\
\text { sobre a atividade } \\
\text { eletromiográfica } \\
\text { no vasto medial e } \\
\text { vasto lateral, } \\
\text { durante atividade } \\
\text { de sentar } \\
\text { levantar. } \\
\end{array}$ & $\begin{array}{l}\text { Vinte e cinco mulheres } \\
\text { realizaram a atividade de } \\
\text { sentar levantar em quatro } \\
\text { condições: descalços, e com } \\
\text { salto de } 1,3 \text { e } 5 \mathrm{~cm} \text { de altura. } \\
\text { Atividade EMG foi registrada } \\
\text { a partir de VM e VL durante a } \\
\text { atividade }\end{array}$ & $\begin{array}{l}\text { A relação eletromiográfica } \\
\text { do vasto lateral e vasto } \\
\text { medial não apresentou } \\
\text { alterações significativa. }\end{array}$ \\
\hline $\begin{array}{l}\text { Cronin N. J.; } \\
\text { Barrett R.S.; } \\
\text { Carty C. P. J } \\
\text { Appl Physiol., } \\
2012 .\end{array}$ & $\begin{array}{l}\text { Avaliar os efeitos } \\
\text { do uso habitual } \\
\text { do salto alto no } \\
\text { comportamento } \\
\text { neuromecânico } \\
\text { dos músculos } \\
\text { tríceps sural } \\
\text { durante a marcha. }\end{array}$ & $\begin{array}{l}\text { Grupo } 1: 9 \text { participantes que } \\
\text { usam salto alto com } \\
\text { frequência ( } 40 \mathrm{~h} / \mathrm{semana} \text { ) e } \\
\text { Grupo } 2 \text { (controle): } 10 \\
\text { participantes que usam salto } \\
\text { por menos } 10 \mathrm{~h} \text { semanais. } \\
\text { Ambos os grupos caminharam } \\
\text { sobre uma superfície nivelada } \\
\text { capaz de medir a força de } \\
\text { reação ao solo em duas } \\
\text { situações: calçados de salto }\end{array}$ & $\begin{array}{l}\text { Quando calçados de salto } \\
\text { alto resultou em aumento } \\
\text { substancial das fibras } \\
\text { musculares do } \\
\text { gastrocnêmio e também } \\
\text { aumento na ativação } \\
\text { muscular durante a } \\
\text { marcha, comparando } \\
\text { quando realizaram o } \\
\text { estudo descalço. } \\
\text { Sugerindo que as pessoas }\end{array}$ \\
\hline
\end{tabular}




\begin{tabular}{|c|c|c|c|}
\hline & & alto e descalço. & $\begin{array}{l}\text { que usam salto alto por } \\
\text { longo período podem } \\
\text { comprometer a eficiência } \\
\text { muscular na caminhada, } \\
\text { sendo comum o relato de } \\
\text { desconforto e fadiga } \\
\text { muscular. E também } \\
\text { podem aumentar o risco } \\
\text { de lesão nas fibras. }\end{array}$ \\
\hline $\begin{array}{l}\text { BORTOLI, M. } \\
\text { et al. Revista } \\
\text { Inspirar, } 2010 .\end{array}$ & $\begin{array}{l}\text { Identificar as } \\
\text { alterações na } \\
\text { cintura pélvica } \\
\text { decorrente uso do } \\
\text { sapato de salto } \\
\text { alto na postura } \\
\text { estática. }\end{array}$ & $\begin{array}{l}\text { Participaram do estudo } 25 \\
\text { mulheres que foram } \\
\text { fotografadas, primeiramente } \\
\text { descalças, e após com sapato } \\
\text { de salto alto de } 3 \text { e de } 10 \mathrm{~cm} \text {. }\end{array}$ & $\begin{array}{l}\text { A cintura pélvica e } \\
\text { lordose não sofreram } \\
\text { diferenças significativas } \\
\text { independentemente da } \\
\text { altura de salto alto. }\end{array}$ \\
\hline $\begin{array}{l}\text { ARTUSI, C.; et } \\
\text { al. } \quad \text { Revista } \\
\text { Inspirar, 2010. }\end{array}$ & $\begin{array}{l}\text { Avaliar a relação } \\
\text { entre o formato } \\
\text { do arco } \\
\text { longitudinal } \\
\text { medial e o pico } \\
\text { de torque dos } \\
\text { inversores e } \\
\text { eversores de } \\
\text { tornozelo em } \\
\text { usuárias de salto } \\
\text { alto e as } \\
\text { implicações do } \\
\text { uso contínuo } \\
\text { deste no formato } \\
\text { deste arco. }\end{array}$ & $\begin{array}{l}\text { A amostra foi constituída por } \\
49 \text { usuárias de salto alto } \\
\text { divididas em três grupos de } \\
\text { acordo com a altura de salto } \\
\text { mais utilizada no seu dia-a- } \\
\text { dia. Foi mensurado o pico de } \\
\text { torque da musculatura } \\
\text { inversora e eversora do } \\
\text { tornozelo a } 30 \% \text { s e } 60 \% \\
\text { através do dinamômetro } \\
\text { isocinético e avaliado o } \\
\text { formato do arco longitudinal } \\
\text { medial pela Linha de Feiss. }\end{array}$ & $\begin{array}{l}\text { Não ocorreram relações } \\
\text { estatisticamente } \\
\text { significativas entre o } \\
\text { formato do arco } \\
\text { longitudinal medial e o } \\
\text { pico de torque da } \\
\text { musculatura avaliada, nem } \\
\text { associações entre as } \\
\text { diferentes alturas de salto } \\
\text { e o formato deste arco. }\end{array}$ \\
\hline
\end{tabular}

\section{V - DISCUSSÃO}

O salto alto, por apresentar valor estético entre as mulheres, tem sido muito utilizado, tornando-se uma opção diária no ambiente de trabalho (TEDESCHI, FILHO et al. 2007).

$\mathrm{O}$ ciclo da marcha se modificada durante o uso de salto alto, com passos mais curtos e lentos, onde ocorre um aumento da flexão do joelho durante o toque do calcanhar no chão, aumento no tempo de duração da fase de apoio, aumento na sobrecarga sobre a região de antepé, alem da redução da amplitude articular durante a fase de balanço (SANTOS,

S. A. et al., 2008).

A flexão plantar mantida durante a marcha associada ao uso do salto alto pode levar a um encurtamento dos músculos gastrocnêmios e sóleo, restringindo a dorsiflexão do tornozelo (CANDOTTI et al., 2012).

Durante a marcha associada ao uso de salto alto, há uma área menor do pé a ser retirada do solo, pois somente o antepé encontra-se apoiado no chão, sendo assim, menor deverá ser o movimento realizado pelo tornozelo para retirar o pé do chão e menor o tempo de realização nesta fase da marcha. Na marcha, a fase de duplo apoio permite ao corpo maior estabilidade, pois a base 
de sustentação se encontra aumentada. Com o uso do salto alto, a tíbia se projetada à frente, necessitando de menos tempo para realização da dorsiflexão, e assim sendo um menor tempo da fase de duplo apoio, podendo gerar desequilíbrio (LIMANA et al., 2012).

Quando descalço, o pé pode gerar uma variedade de adaptações muito maior quando comparada com a utilização de calçado com salto alto. Quando calçado com salto alto o pé e o tornozelo se apresentam limitados a novos movimentos, por se encontrarem em um implemento de maior rigidez e altura, podendo diminuir o mecanismo de propriocepção e a estabilidade corporal (MANN; TEIXEIRA; MOTA, 2008).

A distribuição do peso corporal também fica alterada durante o uso do salto alto, pois reduzi a pressão no calcanhar deslocando para o antepé, gerando mudanças nos picos de pressão das cabeças dos $3^{\circ}, 4^{\circ}$ e $5^{\circ}$ metatarsos para $\mathrm{o} 1^{\mathrm{o}}$ e $2^{\circ}$ metatarsos, tornando essas regiões mais propensa à metatarsalgias (LUNES et al., 2008) e (PEZZAN; SACCO; JOÃO, 2009).

Os calçados de salto alto deslocam o centro de massa do corpo anteriormente, posicionando o tornozelo em flexão plantar, tornando o tríceps sural mais encurtado, o que diminui a capacidade de força contrátil do mesmo, podendo aumentar a incidência de entorses e fraturas de tornozelo e pé (PEZZAN; SACCO; JOÃO, 2009).

Com o uso de salto alto, a flexão plantar ocorre proporcionalmente a altura do salto, gerando deslocamento anterior do corpo para proporcionar equilíbrio (BERTOCELLO, D. et al, 2009).

Essa flexão plantar sustentada durante o uso de calçado de salto alto também pode ocasionar, além do desequilíbrio muscular, uma instabilidade articular. O entorse de tornozelo em inversão é o mecanismo de lesão mais comum (LUTOSA et al., 2011).

São poucas as pesquisas que relacionam o uso de saltos e seus efeitos na coluna vertebral (PEGORETI et al., 2005).

O uso do salto alto pode estar associado muitas vezes com dores na coluna lombar. American Chiropractic Association relata que “A utilização, por tempo prolongado, de salto alto pode gerar aumento da curvatura lombar e anteversão pélvica"; a American Physical Therapy Association diz que "Usar salto alto aumenta extensão do coluna". Estudos anteriores mostram que utilizar salto alto causa alterações insignificantes na curvatura da coluna, porém esses estudos apresentam uma amostra pequena (RUSSELL, B.S et al,, 2012).

A curvatura da coluna lombar se adapta a cada ciclo da marcha, que segue o ritmo dos passos e das passadas, apresentando oscilações sincrônicas com a movimentação dos membros inferiores (FAVERA et al., 2010)

De acordo com o estudo realizado por PEGORETTI et al, 2005 concluíram que durante a marcha com salto alto ocorre retificação da coluna lombar. Já MINOSSI et al., 2012 concluíram que a utilização de salto 
alto não modificou significativamente os ângulos das curvaturas torácica e lombar da coluna vertebral das candidatas avaliadas por eles.

\section{VI - CONCLUSÃO}

A presente revisão de literatura trouxe informações importantes a respeito das alterações músculo esqueléticas de coluna lombar e membros inferiores, bem como alterações de equilíbrio corporal advindas do uso de salto alto. Alterações na angulação da coluna lombar, na angulação do joelho, na angulação tíbiotársica e na conformação do arco plantar, predispõem a população feminina a lesões, artralgia e alterações posturais.

\section{VII -REFERÊNCIAS}

1 - ARTUSI, C.; PIOVESAN, V.; MENTA, M.R.; PIAZZA, PIMENTEL, G. L.; ALMEIDA, C.R. Relação entre o formato do arco longitudinal medial do pé e o pico de torque dos inversores e eversores de tornozelo em usuárias de sapatos de salto alto. Revista Inspirar, v.1, n.4, p. 104-113, 2010.

2 - BERTOCELLO, D.; SÁ, C. S. C.; CALAPODÓPULOS, A. H.; LEMOS, V. L. Equilíbrio e retração muscular em jovens estudantes usuárias de calçado de salto alto. Fisioterapia e Pesquisa, v. 16, n. 2, p. 107 112, 2009.

3 - BORTOLI, M.; SOUTO, M.; RIGON, D.; SBRUZZI, G.; PIMENTEL, G.L.; ALMEIDA, C.R. Influência do sapato de salto alto na cintura pélvica. Revista Inspirar, v.1, n.4, p. 104-113, 2010.
4 - CANDOTTI, C. T.; CARVALHO, K. V.; TORRE, NOLL, M.; VARELA, M. Ativação e co-contração dos músculos gastrocnêmio e tibial anterior na marcha de mulheres utilizando diferentes alturas de saltos. Revista Brasileira de Ciência do Esporte, v. 34, n. 1, p. 27 - 39, 2012.

5 - CRONIN, N.J.; BARRETT, R.S.; CARTY, C.P. Long-term use of high-heeled shoes alters the neuromechanics of human walking. Journal of Applied Physiology, 2012.

6 - EDWARDS, L.; DIXON, J.; KENT, J.R.; HODGSON, D. ; WHITTAKER, V.J. Effect of shoe heel height on vastus medialis and vastus lateralis electromyographic activity during sit to stand. Journal of Orthopaedic Surgery and Research, v.3, n. 2, p. 1-7, 2008.

7 - FAVERA, J. M. D.; PRAKE, G. I.;

TEIXEIRA, C. S.; ALVES, R.F.; LEMOS, L. F. C.; MOTA, C. B. Análise cinemática na compreensão da postura de membros inferiores durante a marcha humana. Revista Salusvita - Bauru, v. 29, n. 1, p 69 -78, 2010.

8 - JOÃO, S. M.A.; CARDILLO, C.; KIELING, I.; PEZZAN, P. A. O.; SAUER, J. F. Análise do arco longitudinal medial em adolescentes usuárias de calçados de salto alto. Fisioterapia e Pesquisa, v. 19, n. 1, p. 20 $-25,2012$.

9 - LIMANA, M.D.; DEPRÁ, P.P.; CAPELINI, J.C.; MORI M.L.G.T.S. Efeito agudo do calçado de diferentes alturas sobre o comportamento angular do tornozelo.

Fisioterapia e Pesquisa, v.10, n. 3, 2012.

10 - LUNES, D. H.; MONTE, R. W.; SANTOS, C. B. A.; CASTRO, F. A.; SALGADO, H.S. A influência postural do salto alto em mulheres adultas: análise por biofotogrametria computadorizada. Revista Brasileira de Fisioterapia, v. 12, n. 6, 2008.

11 - LUTOSA, L.; FURBINO, A. P. M.; CRUZ, C.S.; ANDRADE, I. L. L.; 
VENTURINI, C. Análise do pico de ativação do glúteo máximo na marcha em mulheres com instabilidade do tornozelo. Fisioterapia em Movimento, v. 24, n. 3, p. 463- 470, 2011.

12 - MANN, L.; TEIXEIRA, C.S.; MOTA, C. B. A marcha Humana: Interferências de cargas e de diferentes situações. Arquivos de Ciências da Saúde da UNIPAR, v. 12, n. 3, p. 257 - 264, 2008.

13 - MINOSSI, C.E.S; CANDOTTI, C.D; BACCHI, C.; NOLL, M.; CASAL, M.Z. Avaliação da coluna lombar e torácica nas situações com salto alto e com os pés descalços com o instrumento arcômetro. Fisioterapia e Pesquisa, v.19, n.3, p. 196-203, 2012.

14 - MORAES FILHO, M. C.; REIS, R.A.; KAWAMURA, C. M. Avaliação do padrão de movimento dos joelhos e tornozelos durante a maturação da marcha normal. Acta Ortopédica Brasileira, v. 18, n. 1, p. 23 - 25, 2010.

15 - MORAES, G. F. S.; ANTUNES, A. P.; REZENDE, E. L.; OLIVEIRA, P. C. R. Uso de diferentes tipos de calçados não interfere na postura ortostática de mulheres hígidas. Fisioterapia em Movimento, v. 23, n. 4, p 565 - 574, 2010.

16 - MORAES, G. F. S.; ANTUNES, A. P.; REZENDE, E. L.; OLIVEIRA, P. C. R. Avaliação da atividade eletromiográfica com ou sem o uso de diversos tipos de calçado, em diferentes planos de locomoção. Fisioterapia em Movimento, v. 25, n. 3, p. 507 - 516, 2012.

17 - NAZARIO, P.F.; SANTOS, J. O. L.; AVILA, A. O. V. Comparação da distribuição de pressão plantar em sujeitos com pés normais e com pés planos durante a marcha. Revista Brasileira de cineantropometria \& Desempenho Humano, v. 12, n. 4, p. $290-$ 294, 2010.

18 - PEGORETTI, C.; BRENZIKOFER, R.; WITTIG, D.S.; BENETTI, F.A.; DEPRÁ, P. P.; CAMPOS, M.H. A influência do aumento da altura dos saltos dos calçados na lordose lombar. Revista de Ciências Médicas Capinas, v. 14, n. 5, p. 425 - 432, 2005.

19 - PEZZAN, P. A. O.; SACCO, I. C. N.; JOÃO, S. M. A. Postura do pé e classificação do arco plantar de adolescentes usuárias e não usuárias de calçados de salto alto. Revista Brasileira de Fisioterapia, v. 13, n. 5, p. 398 - 404, 2009.

20 - RUSSELL, B. S.; MUHLENKAMP, K. A.; HOIRIIS, K.T.; DESIMONE C.M. Measurement of lumbar Lordosis in static standing posture with and without high-heeled shoes. Journal of Chiropractic Medicine, v. 11, n.3, p. 145-153, 2012.

21 - SANTOS, C. L.; NORONHA, D. O.; GOMES, C. A.; FERNANDES, P. R.;

FILHO, F. J. Repercussões biomecânicas do uso de salto alto na cinemática da marcha: um estudo retrospectivo de 1990 a 2007. Revista de Educação Física, 2008.

22 - TEDESCHI FILHO, W; PICCINATO, C. E.; MORIYA, T.; JOVILIANO, E. E.; DEZOTTI, N. R.A. Influência da altura do alto de sapatos na função venosa de mulheres jovens. Jornal Vascular Brasileiro, v. 6, n. 4, p. $352-358,2007$.

23 - VIANNA, D. L.; GREVE, J.M.D.

Relação entre a mobilidade do tornozelo em pé e a magnitude da força vertical de reação do solo. Revista Brasileira de Fisioterapia, v. 10, n. 3, p. $339-345,2006$. 